\title{
A Case of Metastatic Hemangiopericytoma Occurring 16 Years After Initial Presentation: With Special Reference to the Clinical Behavior and Treatment of Metastatic Hemangiopericytoma
}

\author{
Itsuo Fujita', Teruo Kiyama ${ }^{1}$, Kazumitsu Chou', \\ Hitoshi Kanno ${ }^{1}$, Zenya Naito ${ }^{2}$ and Eiji Uchida $^{1}$ \\ ${ }^{1}$ Surgery for Organ Function and Biological Regulation, Graduate School of Medicine, Nippon Medical School \\ ${ }^{2}$ Department of Integrative Pathology, Graduate School of Medicine, Nippon Medical School
}

\begin{abstract}
A 40-year-old woman was referred to our Department of Surgery because of an abdominal wall mass. Sixteen years earlier, she had undergone surgical resection of an inguinal tumor that had been diagnosed as a hemangiosarcoma. Fourteen months after the initial resection, the tumor recurred locally, and complete resection was performed. Twenty-nine months later, computed tomography showed multiple metastatic tumors in the lung. All these tumors were resected during thoracoscopic surgery. Thirteen years after the patient's 3rd operation, a firm mass was detected in the left lower quadrant of the abdominal wall. Magnetic resonance image showed a well-defined mass with heterogeneous contrast enhancement within the rectus abdominis muscle. Positron emission tomography-computed tomography demonstrated no recurrent tumors other than this mass. Complete resection was performed. Microscopic examination showed that this tumor was composed of hypercellular spindle cells and staghornshaped blood vessels. The average number of mitotic figures was 28 per 10 high-power fields. Immunohistochemical examination of the tumor showed focal positivity for CD34. Therefore, the tumor was diagnosed as a metastatic hemangiopericytoma with malignant potential. Careful long-term follow-up is required because metastases can develop after an extended disease-free interval. Aggressive surgical treatment is recommended for distant metastases. (J Nippon Med Sch 2009; 76: 221-225)
\end{abstract}

Key words: metastatic hemangiopericytoma, pulmonary metastases, curative surgical treatment, clinical behavior

\section{Introduction}

Hemangiopericytoma is a rare vascular tumor first described by Stout and Murray ${ }^{1}$ in 1942. This tumor arises from the pericytes of Zimmerman. Although hemangiopericytomas can occur anywhere capillaries are found, the most frequent sites are the lower extremities, pelvic fossa, and retroperitoneum ${ }^{2,3}$. After curative surgical treatment,

Correspondence to Itsuo Fujita, MD, Department of Surgery, Nippon Medical School, 1-1-5 Sendagi, Bunkyo-ku,

Tokyo 113-8603, Japan

E-mail: fujitai@nms.ac.jp

Journal Website (http://www.nms.ac.jp/jnms/) 


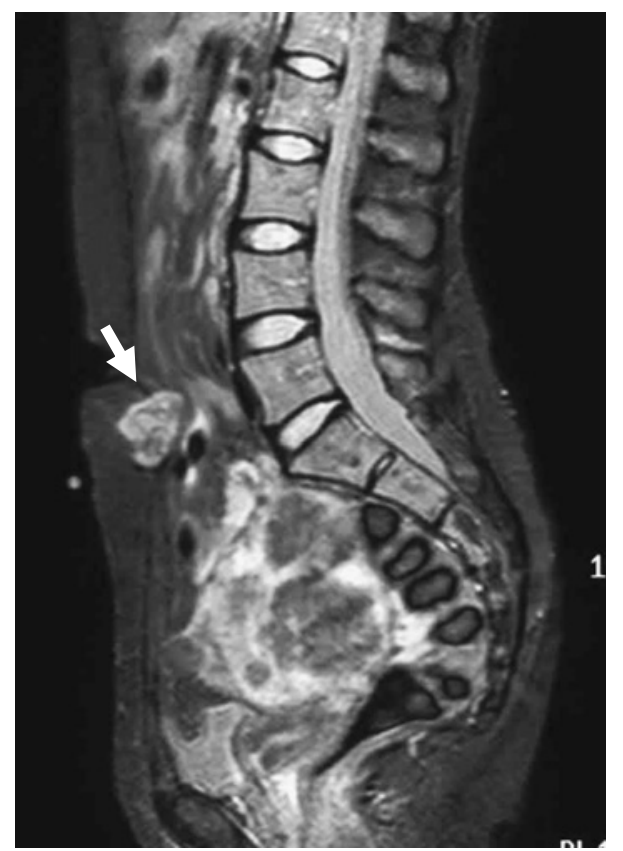

Fig. 1 Magnetic resonance image demonstrated an irregularly shaped, well-defined mass with heterogeneous contrast enhancement within the left rectus abdominis (arrow).

recurrent tumors or metastatic tumors or both develop in some patients with hemangiopericytomas ${ }^{2.3}$. The lungs are the most common metastatic site, followed by the bones and the liver ${ }^{2-4}$. However, predicting the clinical behavior of this tumor after initial resection and determining the appropriate treatment for recurrent or metastatic tumors can be difficult. We report a case of metastatic hemangiopericytoma that occurred 16 years after initial presentation and discuss the clinical behavior and treatment of metastatic hemangiopericytoma.

\section{Case Report}

A 40-year-old woman was referred to our Department of Surgery because of an abdominal wall mass. Sixteen years earlier she had undergone surgical resection at another hospital of an inguinal tumor that had been diagnosed as a hemangiosarcoma. Fourteen months after the initial operation, the tumor recurred locally. She was referred to our hospital for examination and treatment of the inguinal tumor. This tumor was approximately $4 \mathrm{~cm}$ in diameter. Angiography

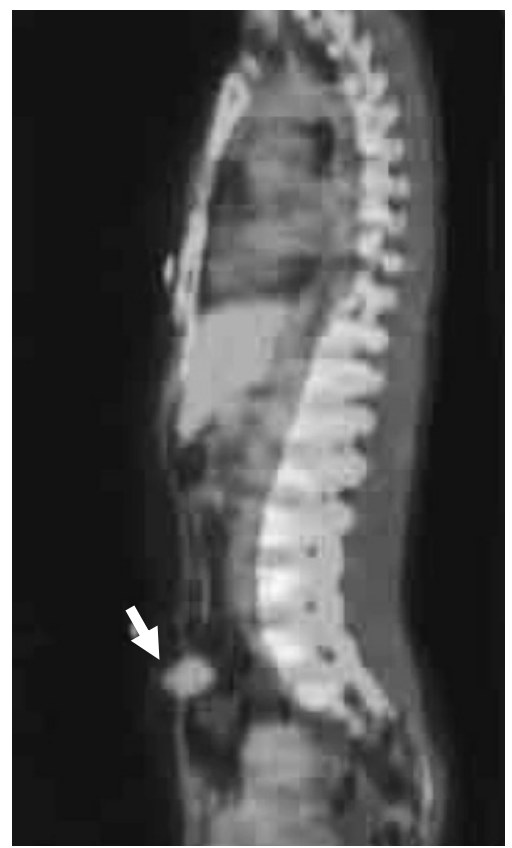

Fig. 2 Positron emission tomography-computed tomography showed increased abnormal uptake at the umbilical region (arrow). Except for this mass, no recurrent or metastatic tumors were detected.

demonstrated a hypervascular tumor fed mainly by the internal iliac artery. Following the arterial administration of cisplatin, local wide resection with curative intent was performed. This patient also received $60 \mathrm{~Gy}$ of postoperative radiotherapy. Twenty-nine months later, computed tomography revealed multiple metastatic tumors in the lung. The patient was treated with a subcutaneous infusion of interleukin 2 at a dose of 700,000 units (73 courses) followed by the resection of all lung metastases during thoracoscopic surgery. Thirteen years after the patient's 3rd operation, the patient found a firm mass in the left lower quadrant of the abdominal wall. On physical examination, the mass was irregularly shaped, firm, and round, measuring about $5 \mathrm{~cm}$ in diameter. Magnetic resonance imaging showed a well-defined mass with heterogeneous contrast enhancement within the rectus abdominis muscle (Fig. 1). Positron emission tomographycomputed tomography demonstrated no recurrent or metastatic tumors other than this mass (Fig. 2). Pathologic examination of a specimen obtained by core needle biopsy revealed metastasis from a hemangiopericytoma. Therefore, we performed 


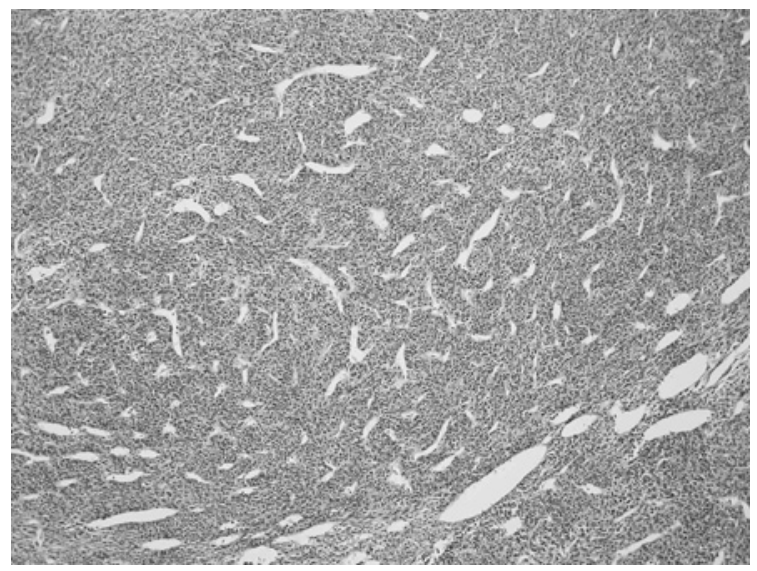

Fig. 3 Pathologic examination showed a solid tumor consisting of hypercellular spindle cells and staghorn-shaped blood vessels. (HE stain, $\times 100$ )

complete resection of this mass. The gross appearance was a $50 \times 45-\mathrm{mm}$, solid and encapsulated mass with focal necrosis and hemorrhage. Microscopic examination showed that this tumor was composed of hypercellular spindle cells and staghorn-shaped blood vessels (Fig. 3). The average number of mitotic figures was 28 per 10 high-power fields. On immunohistochemical examination, the tumor was focally positive for CD34 (Fig. 4) but was negative for $\alpha$-smooth muscle actin, desmin and keratin. The MIB-1 grade, a cell proliferation index, was $50 \%$ to $60 \%$. Therefore, the tumor was diagnosed as a hemangiopericytoma with malignant potential. The patient was discharged on the $12^{\text {th }}$ day after surgery. She remains well 18 months after radical surgical treatment with no evidence of recurrence. The clinical course from initial presentation until the present is summarized in Table 1.

\section{Discussion}

The prognosis of hemangiopericytoma is generally favorable, although recurrent tumors or metastatic tumors or both develop in some patients after curative surgical treatment. Enzinger et al. ${ }^{4}$ have reported that $17 \%$ of 93 patients had metastases and $14 \%$ died of the disease. They have also reported a 10 -year survival rate of $70 \%{ }^{4}$. In a more recent study of 25 cases by Espat et $\mathrm{al}^{2}$, the relapse rate at

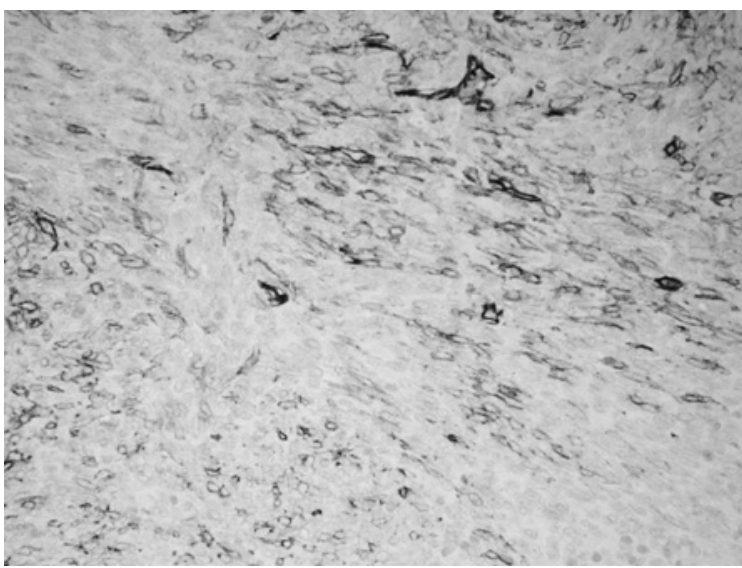

Fig. 4 On immunohistochemical examination, the tumor was focally positive for CD34. $(\times 400)$

distant sites was $20 \%$ and the overall 5-year survival rate was $86 \%$. On the other hand, local failure occurred in $32 \%$ of the patients treated with curative intent ${ }^{3}$. In previous reports, high local failure rates have been observed for tumors of epidural or pelvic/retroperitoneal origin, regardless of whether wide local resection had been performed ${ }^{3}$. However, it has also been suggested that local recurrence is not an indicator of poor prognosis in these patients ${ }^{3}$. Therefore, these results suggest that hemangiopericytoma has a low diseaseassociated mortality rate.

Interestingly, the interval to disease recurrence is longer than that reported for other sarcomas, and metastases can develop following an extended disease-free interval, possibly contributing to the favorable prognosis. Spitz et $\mathrm{al}^{3}{ }^{3}$ have reported that the median times to local failure and distant failure were 29 and 36.5 months, respectively, in patients with hemangiopericytoma, and 18 and 13 months, respectively, in patients with other localized soft sarcomas of the extremities. Disease recurred in some patients after a disease-free interval of more than 5 years. According to previous reports, the interval from initial diagnosis until the detection of metastases ranges from 1 to 14 years ${ }^{4}$. Schirger et al. ${ }^{5}$ have reported on a patient with recurrences up to 26 years after initial curative resection. In addition, during the follow-up period, recurrences and metastases can be repeatedly found, even if complete resection has been performed. Enzinger and $\mathrm{Smith}^{4}$ have reported that in 16 patients, tumors 
I. Fujita, et al

Table 1 Summary of Clinical Course

\begin{tabular}{|c|c|c|c|c|}
\hline Status & Tumor site & $\begin{array}{l}\text { Interval from the } \\
\text { initial operation }\end{array}$ & Treatment & $\begin{array}{l}\text { Pathological } \\
\text { diagnosis }\end{array}$ \\
\hline $\begin{array}{l}\text { primary } \\
\text { tumor }\end{array}$ & $\begin{array}{l}\text { right inguinal } \\
\text { region }\end{array}$ & 0 & $\begin{array}{l}\text { (1) local resection with curative intent } \\
\text { (2) adjuvant chemotherapy (CYVADIC*) }\end{array}$ & hemangiosarcoma \\
\hline $\begin{array}{l}\text { local } \\
\text { recurrence }\end{array}$ & $\begin{array}{l}\text { right inguinal } \\
\text { region }\end{array}$ & 14 months & $\begin{array}{l}\text { (1) preoperative chemotherapy }(\mathrm{TAI} * * \text {, cisplatin) } \\
\text { (2) local wide resection } \\
\text { (3) adjuvant radiotherapy }(60 \mathrm{~Gy})\end{array}$ & hemangiopericytoma \\
\hline metastasis & lung & 2 years 5 months & $\begin{array}{l}\text { (1) IL-2 } * * * \text { infusion }(700.000 \text { U, i.s., } 73 \text { courses) } \\
\text { (2) VATS } * * * * \text { (left: } 4 \text { tumors, right: } 6 \text { tumors) }\end{array}$ & hemangiopericytoma \\
\hline metastasis & $\begin{array}{l}\text { abdominal } \\
\text { wall }\end{array}$ & 16 years & (1) local wide resection & hemangiopericytoma \\
\hline
\end{tabular}

recurred 1 time in 11 patinets, 2 times in 3 patients, 3 times in 1 patient, and 4 times in 1 patient. In the present case, the tumor recurred 3 times during a 17-year period: the tumor recurred locally 14 months after the initial presentation, multiple pulmonary metastases developed 29 months later, and a metastatic tumor of the abdominal wall developed 16 years later.

Conventional morphologic criteria for distinguishing a benign hemangiopericytoma from a malignant tumor are helpful for predicting the prognosis. The combination of a tumor larger than 5 $\mathrm{cm}$ in diameter, prominent mitotic activity (more than 4 mitoses per 10 high-power fields), and tumor cell necrosis is reported to be strongly indicative of malignant hemangiopericytoma ${ }^{4,6}$. Several previous reports have suggested that prognosis is related to the size of the tumor ${ }^{4,6}$. The 10-year survival rate of patients with tumors larger than $6.5 \mathrm{~cm}$ is lower than that of patients with tumors smaller than 6.5 $\mathrm{cm}^{4}$. McMaster et al. ${ }^{7}$ have also emphasized that prominent mitotic figures and foci of necrosis are important prognostic factors. In fact, mitotic figures are rare in benign tumors. ${ }^{4}$. It has also been recommended that cytologically bland, mitotically inactive hemangiopericytomas should not be diagnosed as "benign" but rather as "uncertain malignant tumors," because tumors with these features occasionally metastasize ${ }^{6.8}$. According to these criteria, the proper diagnosis in the present case would be hemangiopericytoma with malignant potential.
Surgical excision with curative intent is the standard strategy for locally recurrent masses, distant metastatic lesions and primary tumors, and is associated with an overall favorable outcome $e^{4,7}$. The 5-year survival rate after complete tumor resection is $100 \%$, and treatment with noncurative intent is a significant indicator of a poor prognosis ${ }^{3}$. Auguste et al. ${ }^{9}$ have reported that hepatic and pulmonary metastases respond well to surgical excision when they are the only evidence of recurrence. In fact, McCormick and Gallivan ${ }^{10}$ have also reported on a patient who was still alive 13 years after the resection of a primary tumor and metastatic nodules in the lung. Our present patient underwent several complete resections of primary and metastatic lesions over an 18-year period and remains alive and well. On the other hand, no evidence has suggested that the use of radiotherapy or chemotherapy or both are beneficial for the treatment of primary and recurrent tumors, although radiotherapy has been used to treat metastatic tumors when surgery is no longer feasible ${ }^{11-14}$.

In conclusion, careful life-long follow-up is required for patients with hemangiopericytoma because recurrence and metastases can develop after an extended disease-free interval. Aggressive surgical treatment is recommended for local recurrences and distant metastases. 


\section{References}

1. Stout AP, Murray MR: Hemangiopericytoma. A vascular tumor featuring zimmermann's pericytes. Ann Surg 1942; 116: 26-33.

2. Espat NJ, Lewis JJ, Leung D, et al.: Conventional Hemangiopericytoma. Cancer 2002; 95: 1746-1751.

3. Spitz FR, Bouvet M, Pisters PWT, Pollock RE, Feig BW: Hemangiopericytoma: A 20-year singleinstitution experience. Ann Surg Oncol 1998; 5: 350355.

4. Enzinger FM, Smith BH: Hemangiopericytoma. An analysis of 106 cases. Hum Pathol 1976; 7: 61-82.

5. Schirger A, Uihlein A, Parker HL, Kernohan JW: Hemangiopericytoma recurring after 26 years. Report of a case. Mayo Clin Proc 1958; 33: 347-352.

6. Kempson RL, Fletcher CDM, Evans HL, Hendrickson MR, Sibley RK: Tumors of the soft tissues. In Atlas of tumor pathology, 3rd series. 1998; pp 371-377, Armed Forces Institute of Pathology, Washington DC.

7. McMaster MJ, Soule EH, Ivins JC : HEMANGIOPERICYTOMA A Clinicopathologic Study and long-term Followup of 60 Patients. Cancer 1975; 36: 2232-2244.
8. Angervall L, Kindblom LG, Nielsen JM, Stener B, Svendsen $\mathrm{P}$ : Hemangiopericytoma : a clinicopathologic, angiographic and microangiographic study. Cancer 1978; 42: 2412-2427.

9. Auguste LJ, Razack MS, Sako K : Hemangiopericytoma. J Surg Oncol 1982; 20: 260-264.

10. McCormack LJ, Gallivan WF: Hemangiopericytoma. Cancer 1954; 7: 595-601.

11. Beadle GF, Hillcoat BL: Treatment of advanced malignant hemangiopericytoma with combination Adriamycin and DTIC: a report of four cases. J Surg Oncol 1983; 22: 167-170.

12. Celik I, Bascil N, Yalcin S, et al.: Ifosfamide-based chemotherapy for recurrent or metastatic hemangiopericytoma. Acta Oncol 1997; 36: 348.

13. Staples JJ, Robinson RA, Wen B-C, Hussey DH: Hemangiopericytoma-the role of radiotherapy. Int J Radiat Oncol Biol Phys 1990; 19: 445-451.

14. Ferrari A, Casanova $M$, Bisogno $G$, et al: Hemangiopericytoma in Pediatric Ages. Cancer 2001; 92: 2692-2098.

(Received, May 25, 2009)

(Accepted, June 15, 2009) 